\title{
Model of Impact of Social Networks on Internet Marketing of Enterprises
}

\author{
Rima Zitkiene ${ }^{1, *}$, Vytautas Gircys ${ }^{2}$, Monika Zitke ${ }^{3}$ and Ilona Bartuseviciene ${ }^{4}$ \\ ${ }^{1}$ Mykolas Romeris University, Faculty of Economics and Business, Ateities 20, Vilnius, Lithuania \\ ${ }^{2}$ Mykolas Romeris University University, Faculty of Economics and Business, Ateities 20, Vilnius, \\ Lithuania \\ ${ }^{3}$ Lithuanian Police School, Planning and Administration Devision, Mokslo g. 2, Mastaičiai, Lithuania \\ ${ }^{4}$ Mykolas Romeris University University, Faculty of Economics and Business, Ateities \\ 20, Vilnius, Lithuania
}

\begin{abstract}
.
Research background. The electronic environment has become an integral part of today's marketing environment. The transformation of information technology makes it possible to reach the desired customer through various business instruments, regardless of his location. The number of consumers using the Internet to search for goods and services is increasing. As a result, social networks are gaining in importance from both businesses and consumers. There are currently over 800 social networks in the world. Corporate social networking accounts where a variety of news can be posted: from company start-up history to the latest company prototype news, and often for small businesses, and represents the cost of the website. Most authors point out that the scope of emarketing is wider than online marketing because online marketing refers only to the Internet. Businesses seek to disseminate information about goods through social networks, given their popularity and impact on consumers.

Purpose of the article is to construct the theoretical model that would help to determine how the impact of social networks on online marketing of companies can be assessed.

Methods: analysis of scientific literature, systematization, generalization.

Findings and Value added. Based on the model, proposed by the authors, the elements of Internet marketing are analyzed, as well as research on the importance of social networks in information transfer and communication with the consumer is emphasized and the most commonly used indicators of social networks are singled out.
\end{abstract}

Keywords: social networks; internet marketing; business; enterprises; theoretical model

JEL Classification: $M 30 ; M 37 ; O 31$

${ }^{*}$ Corresponding author: rizit3@mruni.eu 


\section{Introduction}

The electronic environment has become an integral part of the present-day marketing environment. The development of information technologies enables reaching the target customer by using a variety of business instruments, regardless of the location. According to Smith, Chaffey (2005), online marketing is defined as realization of the marketing goals by using digital technologies. There is an increasing number of consumers who use the Internet for the purpose of searching for goods and services. Therefore, both companies and consumers place more focus on social networks. Currently there are over 800 social networks in the world in total. Companies' accounts on social networks enable them to post a variety of news ranging from the establishment history of the company to news involving the latest prototypes developed by the company, thus they often serve as means for saving website costs for small businesses. Studies of researchers' papers show that authors analyse various aspects of online marketing and rely on the theory of online marketing thus revealing its key elements and use various business models for this purpose. Often companies operating on the basis of the principle of the Business-to-Business (B2B) business model tend to be cautious about the impact of online marketing, however, this trend becomes particularly more notable among companies operating in the field of information technologies.

Most authors indicate that the area of application of electronic marketing is broader in comparison to online marketing, because online marketing refers to the Internet only. However, electronic marketing includes all this as well as all other tools of electronic marketing, such as: intranets, extranets, and mobile telephones. On the contrary, ecommerce and electronic business cover a broader scope than electronic marketing. Electronic marketing (e-marketing) refers to presentation of a business or a product to regular Internet users searching for news or information on services or the goods in the virtual space.

Business companies seek to spread information about goods via social networks by taking into account their popularity and the impact on users. Therefore, it is sought to form a theoretical model designed to assist in assessing the impact of social networks on online marketing. To this end, the first priority is given to analysis of the elements of online marketing, highlighting of the impact of social networks in terms of transfer of information and communication with the consumer, as well as presentation of the indicators of the most commonly used social networks.

Strauss, Frost (2001) describes internet marketing as the use of electronic data and programs in planning and realization of the concept of ideas, goods, and services, distribution and pricing in order to develop exchange to meet individual and organizational goals. Most authors indicate that the area of application of internet marketing is broader in comparison to online marketing, because online marketing refers to the Internet only. However, internet marketing includes all this as well as all other tools of internet marketing, such as: intranets, extranets, and mobile telephones. On the contrary, ecommerce and electronic business cover a broader scope than internet marketing. Electronic marketing (e-marketing) refers to presentation of business or a product to regular Internet users searching for news or information on services or the goods in the virtual space.

On the other hand, the review of scientific literature shows that the public uses such terms as: internet, electronic marketing; online marketing; electronic commerce as equivalents or inappropriate wording in the same sense, which is incorrect. According to Schlosser (1999), this is inappropriate because they are different concepts. 
There may be different types of digital marketing, for example, a conventional advertisement on the website or simply a website designed for representation of a company. According to Schlosser, (1999) online marketing is "the company's message concerning their product or service designed to convey information to potential consumers, who use the Internet for the purpose of obtaining the required information". Online marketing can take many forms, including video records, audio records, e-mails, interactive computer games, logos, or official websites. The Internet has become a new communication channel which led to the evolution of the mutual communication methods used by customers and companies. Online marketing is a new marketing, sales, and trademark strategy method enabling companies to reduce the time spent by them on marketing and to reduce costs efficiently. According to customers (Tsang, M.M., Ho, S.C. \& Liang, T.P., 2004), now they can access information easily or purchase desired products or services hassle-free. This encouraged many scientists to begin researching the phenomena of online marketing. According to the research conducted by Schlosser (1999), online marketing is regarded as a reliable source of information in comparison to the conventional marketing tool. The researcher has also claimed that online marketing was "the company's framed message concerning a product or a service designed to convey information to a potential consumer, who uses the Internet and seeks to obtain the required information". The concepts of digital marketing and online marketing are synonymous.

According to researchers Tripathi, P. K. (2018), Grönroos (2004), the elements of online marketing can be divided into two groups.

Table 1. Elements of online marketing.

\begin{tabular}{|c|c|}
\hline General elements & Advanced elements \\
\hline Website - which would also be adapted for mobile devices & Content marketing - blogs \\
\hline Banner advertising & Mobile app advertising \\
\hline Sponsorship & Affiliate marketing \\
\hline Sponsorship & Affiliate marketing \\
\hline SEO (search engine optimization) & Widgets \\
\hline SEM (Search Engine Marketing) & Retargeting ads \\
\hline Email marketing & e-conferences - webinars \\
\hline & Social media marketing \\
\hline
\end{tabular}

Business companies use various business models within the course of their operations in the electronic space. According to Batum, (2016) the initially formed opinion enables claiming that $\mathrm{B} 2 \mathrm{~B}$ should differ from $\mathrm{B} 2 \mathrm{C}$. Batum researched that $\mathrm{B} 2 \mathrm{~B}$ companies tend to emulate B2C companies in their social media strategies. B2C is the most common business model (Jovarauskiené, 2009), therefore multiple unique methods fit under this umbrella. The B2C innovators used such technologies as mobile applications, local advertisements, and repeated marketing in order to be able to give presentations to their customers directly and to make their life easier in the process. For example, by using the "Lawn Guru" application (https://lawnguru.co/) users can easily contact a variety of servicing companies: local lawn mowing services, gardening and yard specialists, or snow clearing experts, etc. $\mathrm{B} 2 \mathrm{G}$ is dominated by large bureaucratic systems designed to ensure transparent governmental procurements (Magutu, 2008). The B2E program consists of three components: online business processes, online management of human resources, and online servicing jobs for the community (Hansen, M. T., 2001)

The C2C model is based on mutual trust within the course of making any sales (Dachyar, M., 2017). The C2B involves cooperation between the consumer and business when the consumer offers services, goods, and information, etc., to a business entity. The 
C2G model describes a direct presentation to the Government Administration or feedback to authorities or a request for information concerning the public sector. The D2C is a new business model with the main goal to push any intermediaries out of the supply chain (Guessous, 2015). This e-business model could not have developed without the help of the Internet. Many business companies applying the B2C model could not survive without social networks, because often the model of their operations is based only on social networks. Sometimes companies make sales even directly via social platform "Facebook" or additional services connected to "Facebook". In case of B2B business, social networks have a greater impact on companies by accelerating the attraction of target consumers.

\section{Social networks and indicators}

The growth of social network websites marks a transition from the conventional singledirection direct communication to communication in the network environment where information is pulled in accordance with the needs and interests of the audience (Shankar et al., 2003). Unlike the conventional consumer, the digital cost-conscious consumer can have more control over the communication process and can take a more proactive approach enabled by the Internet, as a participant in the communication. In addition to this, the social component in social networks turns them into a privileged medium for consumers to disseminate information on trademarks. Trusovas et al. (2009) provided a very good analysis how they generated a word of mouth in comparison to the conventional marketing tools. Besides this aspect, we should also take into account the impact of social media in the context of mobile communications. The emergence of mobile technologies led to the use of social networks in the digital marketing communications (Mort and Drennan, 2002; Yadav et al., 2015). Depending on the type of business or the preferences of the owner of the company, most of the aforementioned elements should be given some serious consideration in order to increase efficiency of online marketing. Online marketing strategy could be applied as means to achieve positive results just like in any other business, whether it was business or e-commerce.

Business companies started using social networks both for communications and digital marketing: from a message about the company's post to direct sales via social networks, when companies need to hire individual specialists to deal exclusively with the company's marketing via social networks.

Having analysed the literature by authors Stavrositu, Carmen, Jinhee, Chung (2014) by types of marketing, we compared the presented indicators of digital marketing most commonly used by companies by the type of marketing used. It was determined that social network marketing had most of the indicators enabling to measure the efficiency of campaigns.

The key indicators of social networks:

Click-through-rate (CTR) is the rate indicating how often people who saw your advertisement clicked on it. CTR is calculated by: the number of clicks on the advertisements divided by the number of times when the advertisement was showed: clicks $\div$ shows $=$ CTR. For example, if you had 5 clicks on your advertisement and 100 shows, then your CTR would be $5 \%$.

Open rate is an index showing the percentage of people who opened your advertisement. This index is most commonly used in lead generation forms, when a contact person opens the form and either fills in the data or not at a later time.

Organic is an organically incoming feed to the social network. The consumer searches for a solution to an encountered problem and eventually gets to your social network page by finding an article on a topic relevant to him/ her, for example, "How to move the data from the company's data repository to cloud computing?". Impression. Shows help estimating the number of people who saw the entry even if they did not click, comment, or react to the 
entry in any other way. Unlike reach, an advertisement or an entry could be shown to the same person (account) several times.

Cost-per-mille (CPM) is an index of paid advertisement showing how much companies paid for each 1000 shows of the advertisement. Shows mean that someone sees the advertisement on social networks, search systems or other marketing platforms.

Conversion rate. This conversion rate index shows the action made by the recipient of the marketing message determined prior to the start of the promotional campaign. In emarketing this is usually associated with acquisition of item $\mathrm{X}$, however, in B2B marketing this could also be associated with the sales funnel. For example, a suspect having downloaded a brochure he/ she is interested in moves to the next phase in the sales funnel and becomes a prospect; marketing specialists refer to this process as conversion.

\section{Methodology}

Based on the analysis of scientific literature, it is expedient to form a model designed to measure the assessment of the impact of companies' social network marketing on companies' operations. The model consists of the essential elements of the social network marketing plan, which act on the basis of three principles. All of these three theoretical principles could serve companies as an aid in developing a social network plan of the company.

The first principle is setting the goal. What is the purpose of communications on a social network. In this case communication refers to any action taken by the company on social networks, which corresponds to certain communication, for example, changing the location of the company in the page description or posting an article. It is important to choose a proper social network when the need for communication arises or it is determined by a department operating at the company and the decision to do so is made. As we have already reviewed, different characteristics are attributed to social networks, which should be taken into account prior to initiation of any communication. Social network "Facebook" is best suited for campaigns designed to raise brand awareness, because it has the biggest audience than any other social network both on a global scale and in Lithuania. At the same time "Facebook" is versatile as it is used by companies operating on the basis of both B2B and $\mathrm{B} 2 \mathrm{C}$ models as well as other e-business models. Social network "LinkedIn" is perfect for targeted leads that can be filtered out by choosing a target audience by exposing this audience to an appropriate/ relevant message. It is recommended choosing "YouTube" in order to share any professional video message/ record of the company. It is recommended choosing "Instagram" for e-commerce sales under the B2C. This network owned by "Facebook" is perfect for publication of great still images. Social network "Twitter" is recommended for using only if additional time and monetary resources are available, because this network has the smallest audience in Lithuania.

Having selected a preferable social network or several of them to be used for communication of the message, it is necessary to determine the aspects to be used for broadcasting the message. The second principle is determination of the aspects. For example, surveying professionals of social networks could serve as means for determination of the key elements and what causes the biggest impact. We believe that it is expedient to highlight the choice of the target audience, because this aspect is pervious to time in order to choose the most appropriate future customer. We also believe that this serves as means for saving funds in the budget reserved for promotions, because the advertisement is not shown to people who may be completely unrelated to the advertised item or service. The scientific literature also mentions such aspects as the analysis of competitors: it enables understanding how often competitors communicate on social networks. Social network "LinkedIn" offers a functionality enabling to view what paid 
advertising is used by competitors. The analysis of competitors is followed by the need to select the type of advertising: communication of advertising in the form of images, texts, or video records. The period and the site of advertising depend on the type of advertising and the budget reserved for this purpose.

The third principle is application of campaign indicators and tracking thereof. Before launching an advertisement it is necessary to establish the performance indicators designed to measure the usefulness of the advertisement to business followed by return on investment. The indicators must be monitored on the same day right after launching the advertising campaign on social networks. First of all, this enables making sure whether the aspects have been arranged properly as this serves as means for taking note that, for example, the target audience is too broad and that it could be narrowed down in order not to waste money. All of the following campaign indicators, including: the number of followers, CTR, CPM, CTA, CPC, CPV, CPS, opening rate, advertisement reach, and consumer engagement, are individually important in order to advertise a preferable message effectively. Even though the respondents mentioned that the CPM index, which shows the price of the advertisement for every 1000 times shown, was used the least, it is the most significant one in order to increase brand awareness in social networks. Review of the determined indicators enables assessment of social network marketing. If the return on investment is zero or a positive one, this means that it was efficient and had a positive impact on social network marketing. This could be reflected by the quantity of conversions, the increasing number of followers, user engagement, which would mean how many users commented, reacted to the post or shared it, also whether there was any increase in awareness, market share, sales, income, or/and profit. If the impact of social networks on marketing was negative, for example, the number of followers, user engagement, awareness, market share decreased or remained the same, or there were no sales or the number of such sales was insignificant, in that case, taking into account the model, it is suggested to try again by both determining the aspects and monitoring the campaign indicators.

\section{Results}

The model of the assessment of the impact of social networks on internet marketing of enterprises was formed under the basis of three principles explored in the methodology part of this paper: 1) setting the goal; 2) determination of the asspects; 3) application of the indicators. The model suggested by the authors is process oriented and allows business companies to determine both advantages and disatvantages. The model is designed to explore positive and negative impacts, which is extremely important to be succesful in benchmarking as well as identifying your company's critical moments as well as possibilities. 


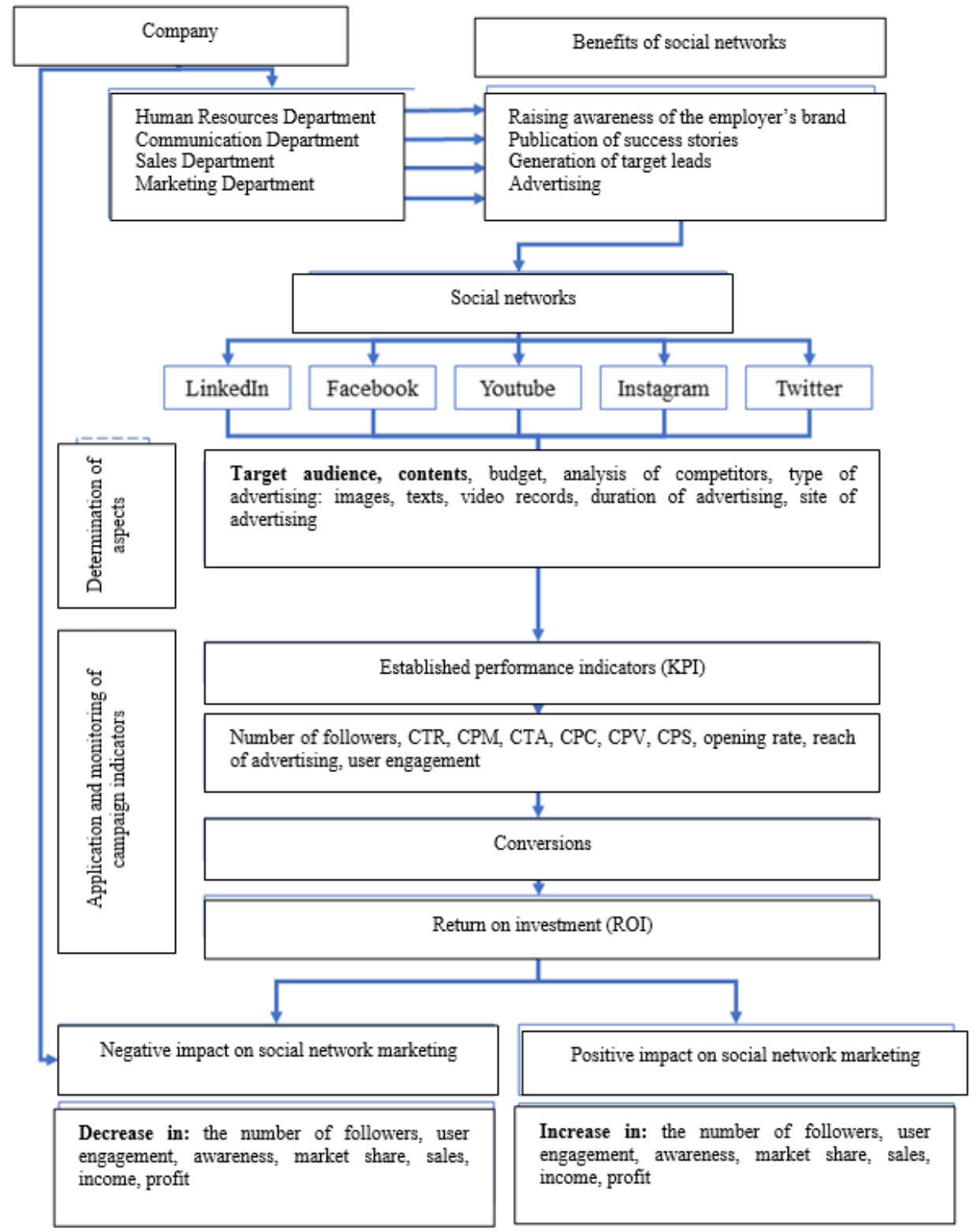

Fig. 1. Model of assessment the impact of social networks on internet marketing of enterprises.

Suggested model is thoeretical and has not been empirically tested yet. The autors argue, that three principle based model could be used by the companies that are engaged in tradicional as well as online sales, as it is believed that communications over social networks could effect the pysical sales as well. This is our first attempt to explore and identify the processes of the possible assessment of the impact of social networks on internet marketing of enterprises with a goal to apply it practically and test it in the companies of variuos sectors in our futher research. 


\section{Discussion and Conclusion}

To sum up the entire model of the assessment of the impact of social networks on companies online marketing, we claim that application thereof enables business companies to determine both advantages and disadvantages in order to assess the return on social network marketing to businesses. The presented paper indicates, that the the goals (KPI) can be clearly measured in digital marketing, unlike in the conventional marketing. This enables a marketing specialist or an agency to clearly define the campaign goals before launching it as well as to measure achievements and ways to plan future operations and investments. This particularly applies to those companies which are just starting to use the social network space. This model presents clear indicators of social networks, which can be used as the bases for assessment of the campaign efficiency. Even though the use of this model is not necessary or mandatory, it is recommended to include it the company's social network marketing plan organization protocol and to continuously improve it by taking into account the situation on the market, because social network marketing is constantly evolving and the identified assessment indicators could be changed in future. This model could be adapted to companies, which make not only online sales, but engage in trade in the physical space as well, because it is believed that communications over social networks could affect physical sales. The autors would like to note, that this theoretical model should be tested in practice for the purpose of the assessment of the impact in order to determine whether it is suitable for all business companies, regardless of the nature and scope of their operations.

\section{References}

1. Chaffey, D., Smith, P. R. (2005). E-Marketing excellence: Planning and optimizing your digital marketing, Oxford, UK. Elsevier.

2. Strauss, J., Frost, R. (2001). Practitioner and academic recommendations for internet marketing and e-commerce curricula. Journal of Marketing Education, 23(2), 91-102.

3. Schlosser, A.E., Shavitt, S., Kanfer, A. (1999). Survey of Internet Users' Attitudes Toward Internet Advertising. Journal of Interactive Marketing, 13(3), 34-54.

4. Tsang, M. M., Ho, S. C., Liang, T. P. (2004). Consumer attitudes toward mobile advertising: an empirical study. International Journal of Electronic Commerce, 8(3), $65-78$.

5. Tripathi, P. K. (2018). Tuning the properties of segmented polyurea by regulating soft-segment length. Journal of Applied Polymer Science, 135(21).

6. Grönroos, C. (2004). The relationship marketing process: communication, interaction, dialogue. Journal of Business \& Industrial Marketing 19(2), 99-113.

7. Batum, T. P., Ersoy, N. F. (2016). The use of social media in b2b marketing communications: an explatory study on Turkish companies, 149. https://www.semanticscholar.org/paper/THE-USE-OF-SOCIAL-MEDIA-IN-B2BMARKETING-AN-STUDY-Batum-Ersoy/d998a63ce3f6b9ea46673444a492475610565ca9.

8. Jovarauskienè, D. et al. (2009). E-business or e-technology? Engineering Economics, 1(61), 83-89.

9. Magutu, P. et al. (2008). E-commerce products and services in the banking industry: the adaptation and usage in commercial banks in Kenya. https://www.researchgate.net/publication/264539689_E-

Commerce_Products_and_Services_in_the_Banking_Industry_The_Adoption_and_U sage_in_Commercial_Banks_in_Kenya. 
10. Hansen, M. T., Deimler, M. S. (2001). Cutting costs while improving morale with b2e management. MIT Sloan Management Review, 43(1), 96-100.

11. Dachyar, M., Banjarnahor L. (2015). Factors influencing purchase intention towards consumer-to-consumer e-commerce. Intangible Capital, 13(5), 1-22.

12. Guessous, I. (2015). Direct to consumer advertising: The case for greater consumer control. Journal of General Internal Medicine, 30(4), 1-2.

13. Shankar, V., Smith, A.K., Rangaswamy, A. (2003). Customer satisfaction and loyalty in online and offline environments. International Journal of Research and Marketing 20, 153-175.

14. Trusov, M., Bucklin, R.E., Koen, P. (2009). Effects of word-of-mouth versus traditional marketing: Findings from an internet social networking site. Journal of Marketing, 73, 90-139.

15. Mort, G.S., Drennan, J. (2002). Mobile digital technology: Emerging issues for marketing. Journal of Database Marketing, 10(1), 9-23.

16. Yadav, M., Joshi, Y., Rahman, Z., (2015). Mobile social media: The new hybrid element of digital marketing communications. Procedia - Social and Behavioral Sciences, 189, 335-343.

17. Stavrositu C., D., Jinhee, K. (2014). Social media metrics: Third-person perceptions of health information. Computers in Human Behavior, 35, 61-67. 